\title{
Fatigue crack growth retardation in spot heated mild steel sheet
}

\author{
B B VERMA and P K RAY* \\ Department of Metallurgical Engineering, *Department of Applied Mechanics and Hydraulics, Regional Engineering \\ College, Rourkela 769 008, India
}

MS received 29 November 2001; revised 24 June 2002

\begin{abstract}
A fatigue crack can be effectively retarded by heating a spot near the crack tip under nil remote stress condition. The subcritical spot heating at a proper position modifies the crack growth behaviour in a way, more or less, similar to specimen subjected to overload spike. It is observed that the extent of crack growth retardation increases with increasing level of overload as well as with increasing spot temperature. It is also observed that modification in crack growth behaviour is a function of location of heating spot and maximum retardation is observed at +5 position.
\end{abstract}

Keywords. Spot heating; overloading; fatigue crack growth retardation; residual stress; delay cycles.

\section{Introduction}

Despite the advances in the understanding of fatigue failure and the consequent improvement in the design of structures and components, fatigue is still the most common cause of service failure. During the growth of a fatigue crack, load excursions in the form of single tensile overload can result in the retardation of crack advance or even complete arrest of the growing fatigue crack (Kumar 1992; Wang et al 1992; Darvish and Johansson 1995; Zheng 1995; Verma and Pandey 1999). Application of a tensile overload on a fatigue cracked ductile solid (cracked under constant $R$ and $\Delta \sigma$ ) results in accelerated crack advance. Subsequent cycling of the material on the same baseline stress shows a prolonged period of decelerated crack extension. The application of an overload cycle introduces various plastic zones ahead of the crack tip (Robin et al 1983; Pandey and Verma 1997). The two most significant plastic zones at a crack tip are overload induced monotonic plastic zone $\left(2 r_{\mathrm{m}}^{\mathrm{OL}}\right)$ and overload induced cyclic plastic zone $\left(2 r_{\mathrm{c}}^{\mathrm{OL}}\right)$ (Pandey and Verma 1997). Due to the presence of the plastic zones near the crack tip, surrounded in an elastically deformed region, the crack tip experiences a squeezing effect. This results into development of residual compressive stress at and around the crack tip. The compressive stress field reduces the available stress at the crack tip and causes a significant reduction in fatigue crack growth rate (FCGR) (Wang et al 1992; Shuter and Geary 1995; Pandey and Verma 1997). The crack retardation zone, i.e. the extent over which retardation of crack is experienced, may be characterized by parameters, $a_{\mathrm{D}}$ (overload affected total crack length) and $N_{\mathrm{D}}$ (delay cycles), and

*Author for correspondence is schematically represented in figure 1 (Verma and Pandey 2000).

Based on the findings reported by Pandey and Verma (1997), a schematic diagram comprising of plastic zones and retardation zones existing ahead of the crack tip, following an overload cycle, is presented in figure $2 \mathrm{a}$. The post overload stress distribution ahead of a crack tip under nil remote stress and stressed condition are illustrated in figure 2b (Robin et al 1983; Pandey and Verma 1997).

Apart from introducing tensile overload cycle/cycles, there are some other methods available to retard a growing fatigue crack. One such method is to heat the whole cross-section under a static load equal to the maximum load experienced in service (Lam and Griffiths 1990). This introduces a residual compressive stress field around the crack tip. However, this could lead to general yielding in the heating area as the yield stress in the section decreases with the increase in temperature. The technique suggested by Harrison (1965) involves direct heating near the crack tip. However, this requires heating at a precise location. Such heating may also damage the surface due to direct exposure to high temperature. More recently, Chen et al (1993) suggested simultaneously localized heating over a large area around the crack tip and overload application as an effective technique to retard a growing fatigue crack. The state of hot spot in association with overload introduces a plastic zone much bigger than that produced by single overload cycle. This is due to drop in yield stress with rise of temperature. The technique of simple overloading and overloading while a spot near crack tip is hot, require controlled loading of the component and structure. It is worth mentioning that a complex structure may require a special fixture to apply an overload of desired level. 
Another technique of fatigue crack growth retardation involves indirect local heating of the region around the crack tip under nil remote stress state (Mohanthy 1996; Ray et al 2002). When a thin sheet of metal is locally heated, it tries to expand laterally. The metal near the centre of the hot spot experiences high temperature. On the other hand the metal near the periphery and outside is exposed to relatively lower temperature. The metal subjected to higher temperature, being comparatively weaker than the surrounding metal, yields plastically (Lancaster 1993; Wulpi 1996), while the relatively cooler surrounding metal undergoes elastic deformation. Thus due to the presence of plastic zone near the crack tip, surrounded in an elastically deformed region, the inner portion of the hot spot experiences a squeezing effect on cooling and hence a residual compressive stress field is set up. As a result of this the fatigue crack may experience retardation during the course of its growth through this zone. The present paper is focussed on the effect of spot heating on crack growth behaviour and retardation parameters, $N_{\mathrm{D}}$ and $a_{\mathrm{D}}$. The overload induced crack growth retardation is well understood, therefore, an attempt has been made to compare the effects of spot heating with the single overload spike modified crack growth behaviour. The regions near the crack tip were also examined under optical microscope to visualize any modification in the microstructure and crack profile as a result of spot heating.

\section{Experimental}

\subsection{Material and test specimen}

The material investigated in the study was a plain carbon steel (C-0.08, Mn-0.42, Si-0.05, S-0.03 and P-0.04) in sheet form of thickness $3.4 \mathrm{~mm}$ and yield stress, $\sigma_{\mathrm{ys}}=$ $267 \mathrm{MPa}$. The single edge notched (SEN) specimens of $170 \times 50 \times 3.4 \mathrm{~mm}$ dimensions in LT-orientation were

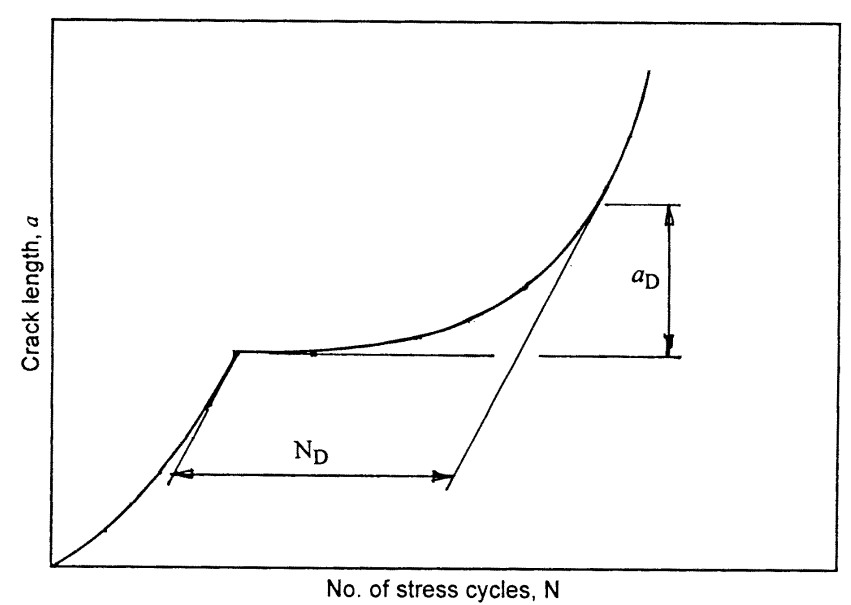

Figure 1. Schematic representation of the effect of an overload spike on fatigue crack growth. used for fatigue test. The specimens were given a flat notch of $6 \mathrm{~mm}$ with the help of a jewellery saw. The notched specimens were fatigue pre-cracked to a total length of $8 \mathrm{~mm}$ before resuming fatigue crack growth study.

\subsection{Fatigue test}

All fatigue tests were carried out using Instron 1603 machine in crack opening mode under constant stress amplitude sinusoidal loading condition at stress ratio, $R=0.2$ and stress range, $\Delta \sigma=87 \mathrm{MPa}$. During the test there was a natural increase in SIFs (i.e. $\Delta K, K_{\max }$ and $\left.K_{\min }\right)$ with crack extension. The range of crack length to width ratio $(a / w)$ maintained during investigation was
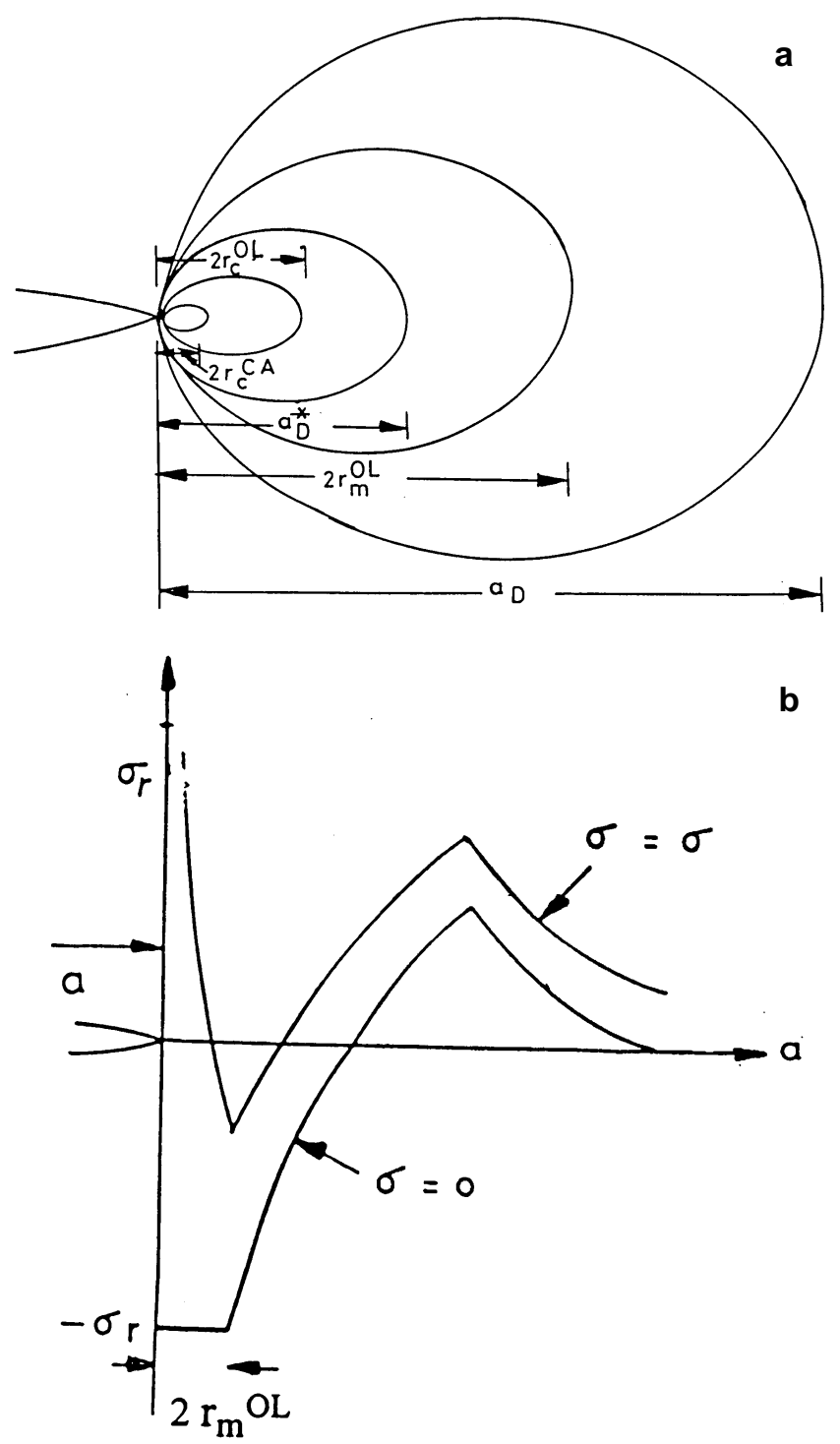

Figure 2. a. Schematic representation of retardation zones and plastic zones ahead of a fatigue crack tip on application of an overload cycle (without crack advance) and b. schematic illustration of stress distribution after application of an overload cycle (without crack advance) at $\sigma=0$ and $\sigma=\sigma$. 
$0 \cdot 16-0 \cdot 50$. The tests were carried out at ambient temperature and at a frequency of $150 \mathrm{~Hz}$. The crack propagation was monitored with the help of a low magnification microscope.

The first few pre-cracked specimens were fatigue tested under constant stress ratio and stress amplitude, and the data generated were used as reference for subsequent sets of experiments. In the second set of experiments, fatigue crack was grown up to a total crack length of $11 \mathrm{~mm}$ (corresponding $\Delta K=23.02 \mathrm{MPa}-\mathrm{m}^{1 / 2}$ ) under same $R$ and $\Delta \sigma$ condition. At this crack length, the specimens were subjected to a single overload cycle. This was followed by subsequent crack growth under the same loading condition. These data were used to compare the retardation with the spot heated specimens. In the third and last set of experiments, specimens were fatigue loaded once again under same $R$ and $\Delta \sigma$ up to a total crack length of $11 \mathrm{~mm}$. At this stage, the specimens were withdrawn from the testing machine, spot heated, and subsequently tested for fatigue crack growth study, maintaining the same stress state.

\subsection{Local heating}

The indirect heating of specimens, through thermal conduction, was done using $7 \mathrm{~mm}$ thick and $12 \mathrm{~mm}$ diameter steel buttons. In each specimen, the spot heating zone was identified and hot end of thermocouples were

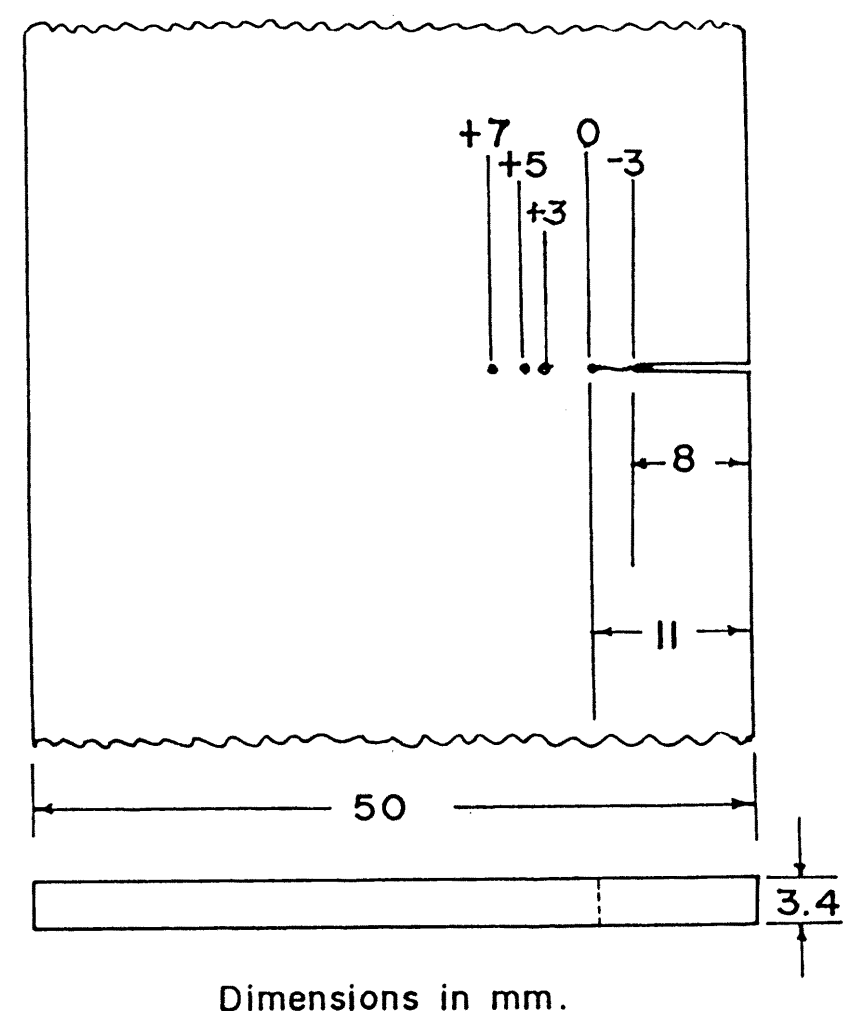

Figure 3. Location of heating spots on specimen. carefully spot welded on either face of each specimen. A well-polished steel button, with a narrow half slit to accommodate the hot end of thermocouple, was placed firmly over the top face of the specimen with the help of an adhesive (M-seal). The oxyacetelene gas flame was applied to the button and temperatures of both the surfaces of the specimen were monitored. The region surrounding the button was protected from direct flame of gas torch by covering it with pieces of asbestos sheet. The final temperature of specimen was achieved by heating specimen approximately at a rate of $9.5^{\circ} \mathrm{C} / \mathrm{s}$. The top face temperature of the specimen was reported and analysed in the present study. The local heating temperature ranged from $300-700^{\circ} \mathrm{C}$.

The tip of crack was used as reference for locating the heating spots. The centres of hot spots were $-3(3 \mathrm{~mm}$ behind the crack tip), 0 (at the crack tip), and $+3,+5$, $+7(3 \mathrm{~mm}, 5 \mathrm{~mm}$ and $7 \mathrm{~mm}$ ahead of the crack tip, respectively). The various heating spots are illustrated in figure 3 .

\section{Results and discussion}

\subsection{Overload modified crack growth behaviour}

The effect of an overload spike on fatigue crack growth behaviour has typically been presented in the form of crack length vs number of stress cycles in figure 4 . The data for SEN specimens tested at $R=0 \cdot 2, \Delta \sigma=87 \mathrm{MPa}$, and subjected to OLR $=1.7$ and 1.9 are illustrated in the figure. It may be seen that introduction of an overload spike caused decrease in crack growth rate $(\mathrm{d} a / \mathrm{d} N)$, i.e. retardation of growing crack. It is also observed that the increase in the level of OLR enhances the extent of retardation at a given crack length (and $K$ level). The increase in crack growth retardation with rise in OLR may be due to increase in $K^{\mathrm{OL}}$ resulting in enlarged

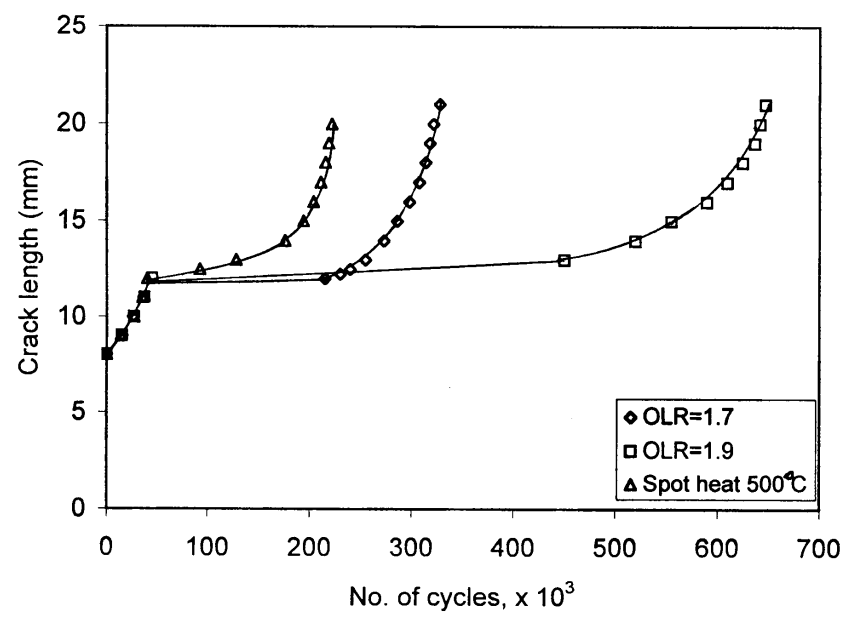

Figure 4. Effect of overloading and spot heating on crack length vs number of stress cycles. 
monotonic plastic zone and/or higher residual stress (Verma and Pandey 1999, 2000). The data for the specimen subjected to spot heating $(R=0 \cdot 2,+5$ position and spot temperature $=500^{\circ} \mathrm{C}$ ) are also incorporated in the figure for the purpose of comparison. It is evident from the figure that spot heating also resulted in an appreciable reduction in crack growth rate.

\subsection{Effect of overloading and spot heating on FCGR vs crack length plots}

FCGR vs $a$ plots for a specimen subjected to an overload spike has typically been illustrated in figure 5 . The overload application is found to result in an immediate acceleration (due to monotonic stretching of the crack on overloading) followed by sudden drop in crack growth rate to a minimum and subsequent slow increase in growth rate with crack extension.

The FCGR vs $a$ plot for spot heated specimens has also been superimposed for the purpose of comparison. As expected it does show a sharp drop in FCGR on spot heating and prolonged retardation. However, there is no indication of immediate crack growth acceleration (on spot heating) due to the absence of an overload spike, which usually stretches an existing fatigue crack. It is evident from the plots that the post spot heating crack extension follows a trend similar to the post overload crack growth behaviour.

\subsection{Effect of OLR on $N_{D}$}

To study the effect of an overload spike on magnitude of retardation, at $R=0.2$ and $\Delta K \approx 23 \mathrm{MPa}-\mathrm{m}^{1 / 2}, N_{\mathrm{D}}$ is presented as a function of OLR in figure 6. $N_{\mathrm{D}}$ appears to be a sensitive function of OLR and suggests significant increase in retardation level with the applied OLR at

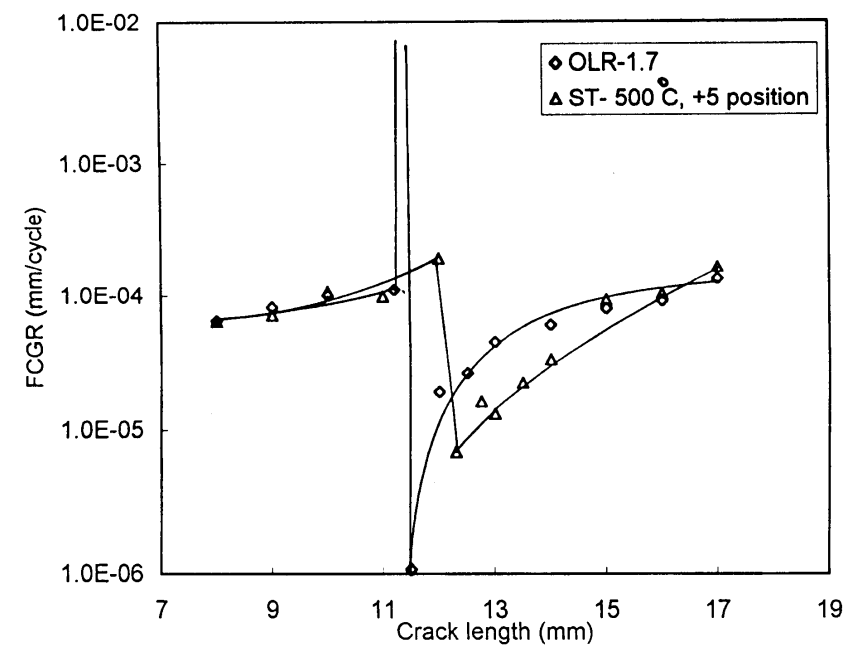

Figure 5. Effect of overloading and spot heating on FCGR vs $a$. constant values of $R$ and $\Delta K$. A linear relation is observed on semilogarithmic scale for the investigated range of OLR and may be expressed as follows

$$
\ln N_{\mathrm{D}}=6.269(\mathrm{OLR})+1 \cdot 257 .
$$

The increase in overload level increases SIF corresponding to overload, $K^{\mathrm{OL}}$ and consequently compressive residual stress (Pandey and Verma 1997; Verma and Pandey 1999). This in turn enhances crack closure level and hence $N_{\mathrm{D}}$ and $a_{\mathrm{D}}$. Similar phenomenon has also been found to occur in other alloy systems (Verma and Pandey 1999, 2000).

\subsection{Effect of spot heating position on crack growth retardation}

The results of spot heating $\left(500^{\circ} \mathrm{C}\right)$ at different locations are presented in figure 7, in the form of crack length, $a$ vs number of stress cycle plots. It may be seen from the figure that there is no appreciable retardation for specimens spot heated at position $-3(3 \mathrm{~mm}$ behind the crack tip). However, heating at 0 (at crack tip), $+3,+5$ and +7 positions (i.e. $3 \mathrm{~mm}, 5 \mathrm{~mm}$ and $7 \mathrm{~mm}$, respectively ahead of the crack tip) resulted into significant retardation of the growing fatigue crack. The magnitude of retardation is observed to increase for the spot heating positions in the order $0,+3,+7$ and +5 (data for specimen spot heated at +3 position has been omitted in figure 7 ). It may also be seen that maximum retardation is observed on spot heating at +5 position amongst the locations studied. This position of heating also registered much wider range of crack length over which retardation effect is experienced. It is worth to note that this spot heating position also recorded lowest slope of the curve (i.e. lowest value of minimum crack growth rate) subsequent

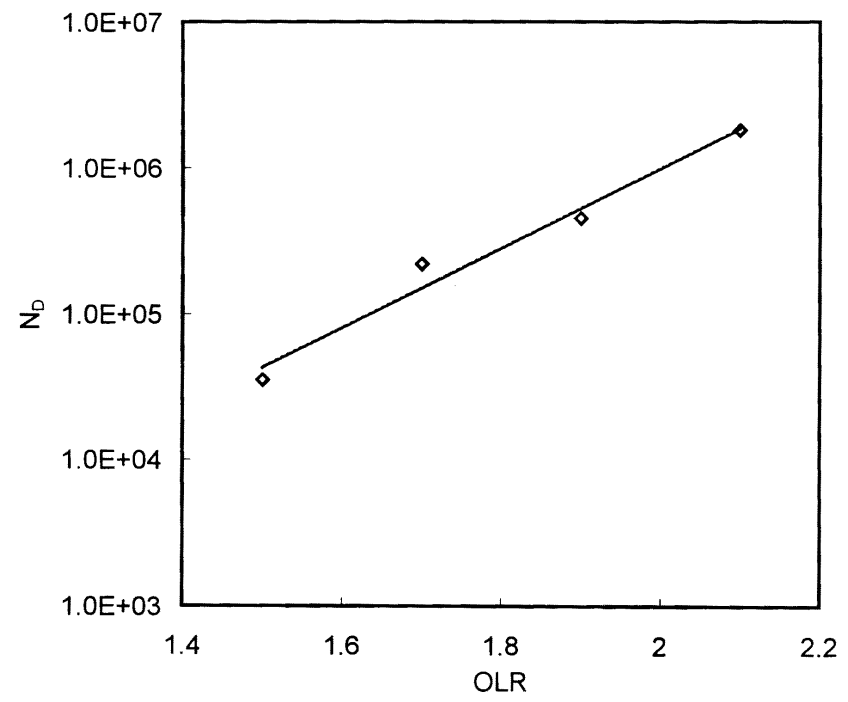

Figure 6. Delay cycles $\left(N_{\mathrm{D}}\right)$ as a function of OLR. 
to spot heating. The above observations clearly indicate that heating at +5 position is most effective in retarding a growing fatigue crack. In case of +7 position the crack tip is located outside the button area. By the time the crack tip reaches the compressive stress zone (i.e. well inside button area), the crack length has considerably increased with a consequent increase in $\Delta K$. Thus crack propagation in the compressive stress zone occurs at a higher value of $\Delta K$ for +7 position compared to +5 position. As a result, spot heating at +5 position is more effective in retarding a crack growth than that at +7 heating position. However, no attempt was made to study the effect of spot heating beyond +7 position.

\subsection{Effect of spot temperature on crack growth behaviour}

The results of spot heating temperature (subcritical) on crack growth behaviour at +5 position are presented in figure 8 . It is evident from the figure that the magnitude of retardation increases with increasing spot temperature. The retardation effect is noticed even on spot heating the specimen to $300^{\circ} \mathrm{C}$. However, the observed magnitude of delay cycles is just $1.85 \times 10^{4}$, whereas the delay cycles increased to a level of $1.34 \times 10^{6}$ on increasing the heating temperature to $700^{\circ} \mathrm{C}$. The increase in extent of retardation may be due to increase in the magnitude of residual compressive stress and/or enlargement of stress field, developed on increasing spot temperature. It is also noticed that increase of spot heating temperature resulted in reduction in crack growth rate at a given crack length (figure 8).

The comparison of overload and spot heating modified $a$ vs $N$ plots indicate that the spot heating affects the crack growth behaviour in a way similar to that of overloading (see figure 4). Examination of FCGR vs $a$

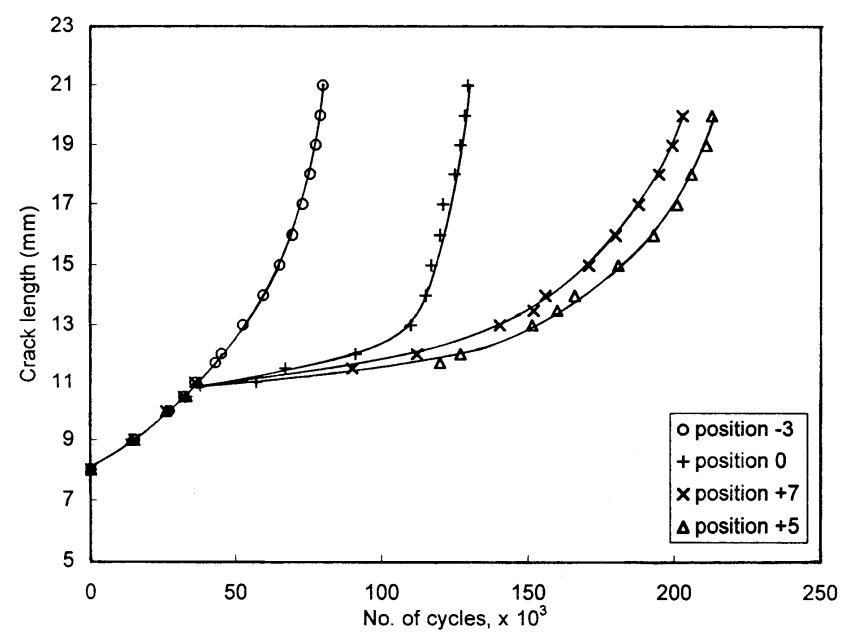

Figure 7. Effect of spot heating positions on crack growth behaviour at a constant heating temperature $\left(500^{\circ} \mathrm{C}\right)$. plots for the specimen subjected to overload spike and spot heating further show nearly similar retardation behaviour (see figure 5). Therefore, the retardation parameters $\left(a_{\mathrm{D}}, N_{\mathrm{D}}\right.$ etc) generally used to characterize the extent of retardation in overloaded specimen, can also be utilized to present the magnitude of retardation on localized heating. The retardation parameters, $a_{\mathrm{D}}$ and $N_{\mathrm{D}}$, obtained from crack length, $a$ and number of stress cycles, $N$ plots (figure 8 ) are presented as a function of spot heating temperature in figure 9 . It may be seen that the retarded crack length and delay cycles both increase with subcritical spot heating temperature. Linear relationships are obtained on semi-logarithmic scale for the investigated levels of $R, \Delta K$ and subcritical spot temperature and may be expressed as

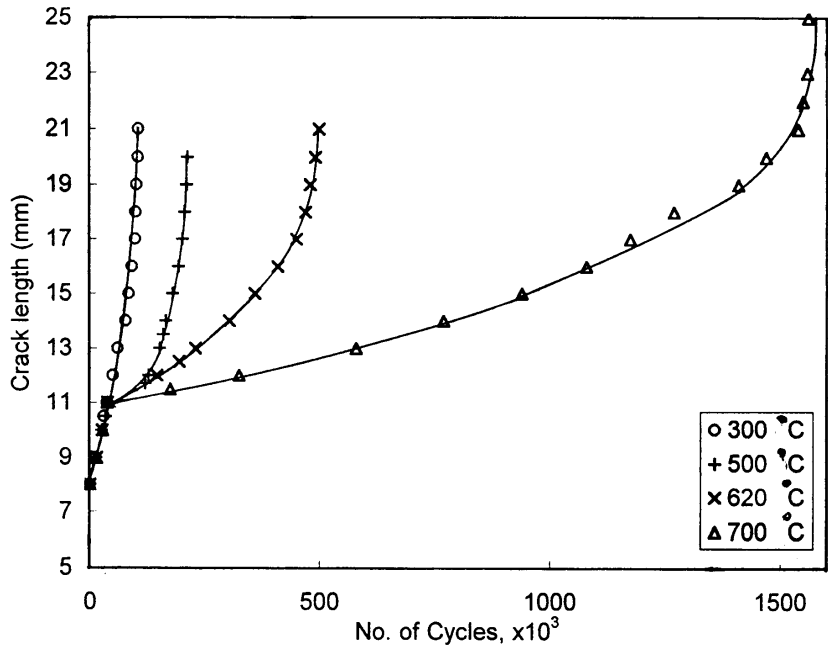

Figure 8. Effect of subcritical spot heating temperatures on crack growth behaviour at heating position +5 .

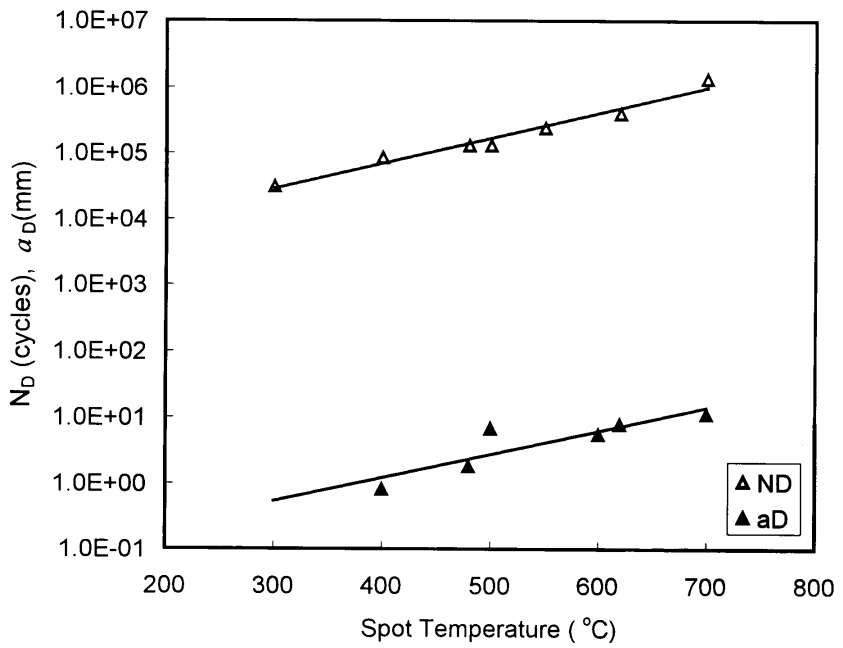

Figure 9. Delay cycles $\left(N_{\mathrm{D}}\right)$ and total retarded crack length $\left(a_{\mathrm{D}}\right)$ as functions of spot heating temperature (heating position +5$)$. 


$$
\begin{aligned}
& \ln N_{\mathrm{D}}=8.828 \times 10^{-3}(\mathrm{ST})+7 \cdot 613, \\
& \ln a_{\mathrm{D}}=9 \cdot 1 \times 10^{-3}(\mathrm{ST})-3.80 .
\end{aligned}
$$

\subsection{Micro-examination of spot heated specimen}

To study the effect of spot heating on microstructure around the crack tip, few as-cracked, and few cracked and subsequently spot heated specimens were examined under optical microscope. The observed microphotographs are presented in figures $10 \mathrm{a}$ and $\mathrm{b}$. It may be seen from the microphotographs that the application of subcritical thermal cycle in a localized region on the mild steel sheet does not significantly alter the microstructure. This confirms that the observed crack growth retardation is not induced by any metallurgical transformation. However, it is worth to note that the spot heating of the specimen has closed the crack. This qualitatively indicates crack closure enhancement on spot heating the fatigue-cracked specimen. A careful examination of cracked and subsequently spot heated specimen further
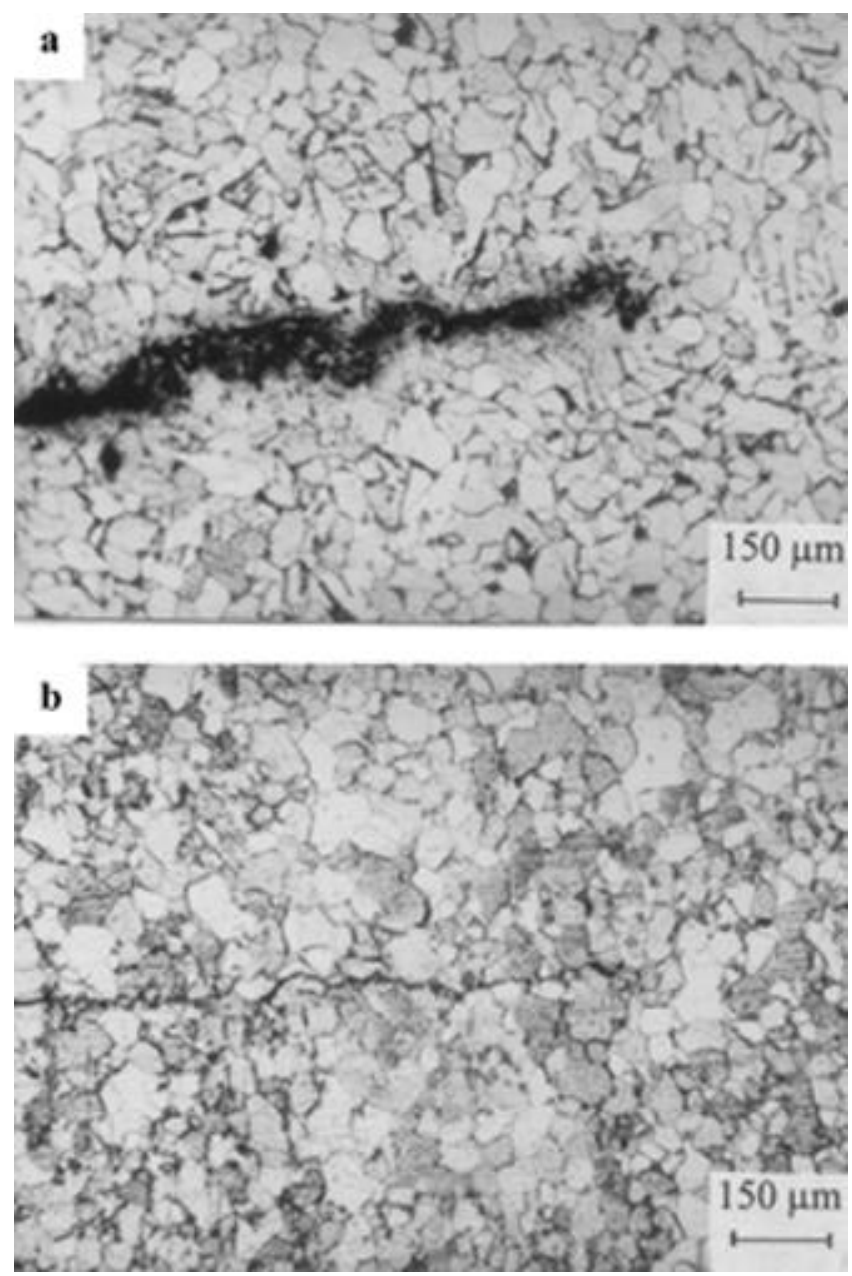

Figure 10. Optical microstructure of a. as cracked and b. cracked and subsequently spot heated specimens. indicates absence of crack tip blunting and deviation. It may be noted that an overload of sufficiently high magnitude results into crack deflection and crack tip blunting apart from introduction of compressive residual stress (Suresh 1996). The fatigue crack remains blunted even after withdrawal of far field tensile stress. A bifurcated, deflected and blunted crack develops a lower effective SIF than a sharp straight crack of the same projected crack length and subjected to an identical value of remote stress. This shows that residual compressive stress may be solely responsible for crack retardation on spot heating (using a gas torch). This suggests that the mechanism of retardation in a spot heated specimen to be different from a specimen subjected to overload cycles.

\subsection{Comparison of overloading and spot heating}

It is clear from the above observation that an overload spike as well as spot heating at a suitable region can result in crack growth retardation. The examination of crack tip of a spot heated specimen reveals no alteration in structure, and absence of crack deviation and blunting. However, it is worth to compare the retardation effect in overloaded and spot heated specimens in terms of OLR and spot temperature respectively. The data from figure 6 $\left(N_{\mathrm{D}}\right.$ vs OLR plot) and figure $9\left(N_{\mathrm{D}}\right.$ vs spot temperature plot) are manipulated and presented in terms of spot temperature (ST) vs OLR in figure 11.

The OLR and spot temperature relationship can also be presented as follows

$$
\mathrm{ST}=710 \cdot 18(\mathrm{OLR})-719 \cdot 98 \text {. }
$$

The above equation and figure 11 are useful in the sense that the spot temperature required to develop retardation equivalent to a given overload level can easily be estimated.

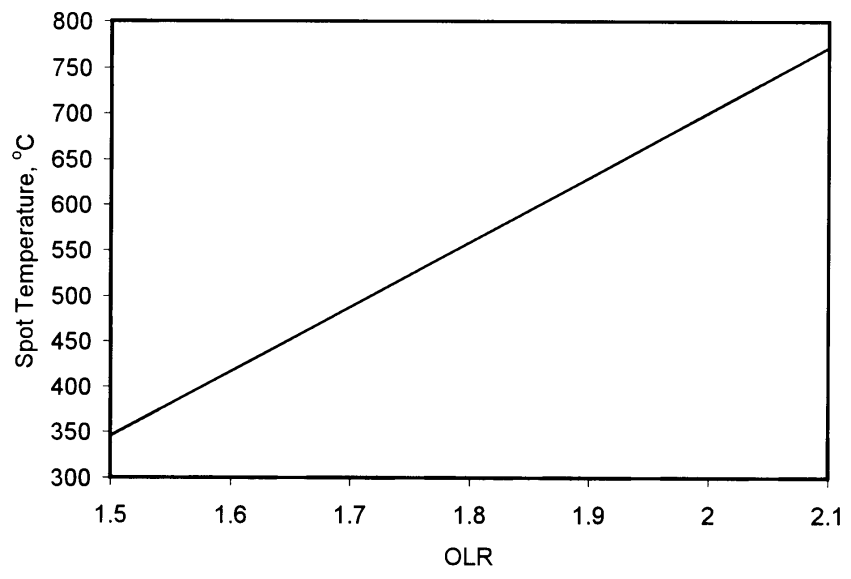

Figure 11. Comparative representation of overloading and spot heating. 


\section{Conclusions}

(I) The spot heating induced crack growth retardation is more or less similar to retardation obtained as a result of an overload spike.

(II) Modification in crack growth behaviour is a function of location of heating spot and the highest level of retardation is observed at +5 position.

(III) Magnitude of retardation increases with the subcritical spot temperature and overload level.

(IV) Subcritical spot heating resulted in no change in microstructure. Also there is no sign of crack deviation and crack tip blunting.

(V) The spot heating induced retardation may be compared with the retardation as a result of overloading and may be related as follows: $\mathrm{ST}=710 \cdot 18($ OLR $)-719 \cdot 98$.

\section{Nomenclature}

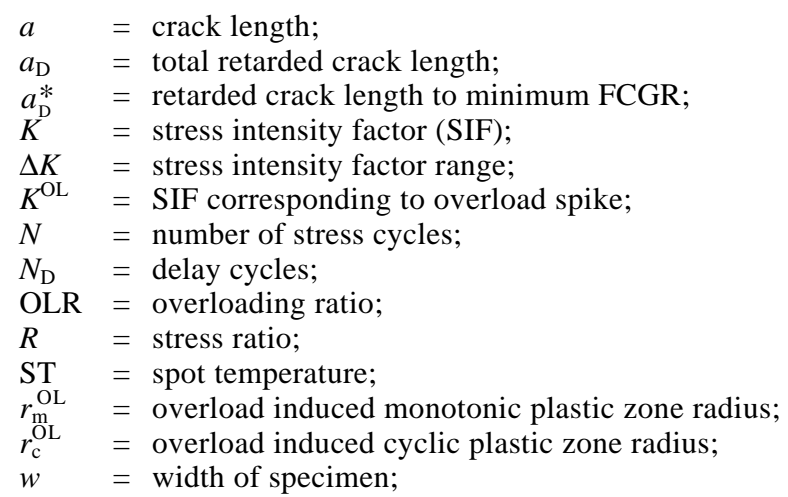

$\sigma \quad=$ nominal stress;

$\sigma_{\mathrm{r}} \quad=$ residual stress;

$\sigma_{\mathrm{ys}} \quad=$ yield stress.

\section{References}

Chen B D, Griffiths J R and Lam Y C 1993 Engng. Fract. Mech. 44567

Darvish M and Johansson S 1995 Engng. Fract. Mech. 52295

Harrison J D 1965 Br. Welding J. 12258

Kumar R 1992 Int. J. Pres. Ves. \& Piping 51329

Lam Y C and Griffiths J R 1990 Theor. Appl. Fract. Mech. 14 37

Lancaster J F 1993 Metallurgy of welding (London: Chapman \& Hall) 5th ed. p. 159

Mohanthy P K 1996 Fatigue crack growth retardation in mild steel sheet, M E Thesis, Regional Engineering College, Rourkela

Pandey R K and Verma B B 1997 Proc. IX ICF (eds) B L Karihaloo et al (Sydney: Pergamon) p. 1285

Ray P K, Verma B B and Mohanthy P K 2002 Int. J. Pres. Ves. \& Piping 79373

Robin C, Lovah M and Pluvinage G 1983 Fatigue Fract. Engng. Mater. Struct. 61

Shuter D M and Geary W 1995 Int. J. Fatigue 17111

Suresh S 1996 Fatigue of materials (Cambridge: Cambridge University Press) 2nd ed. p. 522

Verma B B and Pandey R K 1999 J. Mater. Sci. 344867

Verma B B and Pandey R K 2000 Trans. Indian Inst. Metals 53 291

Wang G S, Palmberg B and Blom A F 1992 Fatigue Fract. Engng. Mater. Struct. 15695

Wulpi D J 1996 Understanding how components fail (Ohio: ASM International)

Zheng X L 1995 Int. J. Fatigue 17331 